\title{
Contributing Factors Affecting the Safety in Construction Sites of Bangladesh
}

\author{
Dr. Farzana Rahman, Mohammed Hossain Ezaz, Dipak Halder, Proshanta Mondal
}

\begin{abstract}
Site safety is an important function regardless of project size. A key goal, which must be met for a successful project, is to finish the project with a good safety record. Construction safety is an important issue in all over the world. Today, developed countries strictly follow the safety procedure to avoid any hazard, accident or fatality. But for a least developed country like Bangladesh, accidents and fatalities are still quite high due to lack of safety management. With the increased volume of construction work in Bangladesh, the need for proper attention in safety issues has become essential for humanitarian, economic and other consideration. Recently, lots of accidents are taking place in construction sites of Bangladesh causing severe injury to death to the workers and pedestrians. There are a number of reasons/factors that these high numbers are widespread to the construction industry that are not found in most other fields. The objective of this research work is to identify and explore the various factor that affect the construction site safety in Bangladesh. A questionnaire surveys was conducted to the reputed construction companies of Bangladesh to examine the present safety situation in construction sites. Nine factors were selected for the survey. The finding shows that $\mathbf{7 8 \%}$ of organizations' from the respondents are conscious about the safety procedure and they usually provide safety measures for the workers. Promotion of safety measures at the working site results in a better working environment, higher productivity and greater contentment among the workers.
\end{abstract}

Keywords-component, formatting, style, styling, insert (key words)

\section{Introduction}

Site safety is an important function regardless of project size. Certainly, larger and more complex construction sites do require more sophisticated safety programs. A key goal, which

Dr. Farzana Rahman

University of Asia Pacific

Bangladesh

Mohammed Hossain Ezaz, Dipak Halder, Proshanta Mondal

Presidency University

Bangladesh must be met for a successful project, is to finish the project with a good safety record. A good safety performance has a strong bearing on being able to accomplish all the other goals of a project. Safety in construction is a prime requisite, but often it gets neglected on the working site. With the increased volume of construction work in Bangladesh, the need for proper attention in safety aspect has become essential for humanitarian, economic and other consideration.

Recently lots of accidents are taking place in construction sites of Bangladesh causing severe injury or even death to the workers and pedestrians. Anyone working in construction has been ingrained with the concept of construction safety for as long as he or she can remember, but construction is still ranked among the highest accident-risk industries in the world especially for a least developed country like Bangladesh. There are a number of reasons that these high numbers are widespread to the construction industry that are not found in most other fields. The objective of this research work is to identify and explore the various factors that affect the construction site safety in Bangladesh in order to reduce the percentage of accidents in individual sites.

\section{Literature Review}

Construction safety relates to safe operation of construction works without bringing any sort of damages or casualties to its internal employees or disturbing its neighbors. The capital of Bangladesh, Dhaka is undergoing significant change due to intensive urbanization. In the last 20 years developers have been purchasing most of available plot of land to build high rise buildings. The industry now employs over three million people and is quite big fund for the developer; but it comes at a high cost for the workers. Recent study in the construction industry identifies followings as the causes of fatal accident [1]:

TABLE I. APPROXIMATE PERCENTAGE of FAtAL ACCIDENT

\begin{tabular}{|c|c|}
\hline Causes & $\begin{array}{c}\text { Approximate percentage of } \\
\text { fatal accident }\end{array}$ \\
\hline Falling Persons & 45 \\
\hline Falling Materials & 14 \\
\hline Transport & 14 \\
\hline Lifting Equipment & 7 \\
\hline Excavation & 7 \\
\hline Electricity & 6 \\
\hline Other Causes & 7 \\
\hline
\end{tabular}


Proc. of the Intl. Conf. on Advances in Civil, Structural and Mechanical Engineering - ACSM 2015.

Copyright (C) Institute of Research Engineers and Doctors, USA .All rights reserved.

ISBN: 978-1-63248-039-2 doi: 10.15224/ 978-1-63248-039-2-102

The situational analysis on labor rights carried out by the Bangladesh Institute of Labor Studies (BILS) shows that the number of construction workplace related accidents was 73 in 2010. The number of workplace related accidents was 56 in 2009 and 100 in 2008. The BILS review, titled 'Situation and condition of workers in the construction industry in Bangladesh: Review 2007,' said that 592 construction workers had died between 2005 and 2007. The report also said that about 68 percent of the workers blamed the lack of safety gear for the deaths and about 43 per cent of them complained that after the accidents, the workers got no compensation from the employers [2].

In the United States, the construction industry accounts for $21.7 \%$ of all occupational fatalities, while making up only $8 \%$ of the workforce [3]. There were 1,225 fatal occupational injuries in the construction sector in 2001 with an incidence rate of 13.3 per 100,000 employed workers [4]. For the same year the construction industry experienced 481,400 nonfatal injuries and illnesses at a rate of 7.9 per 100 full-time workers in the industry [5]. Between 1992 and 2003, employment in construction increased by 44 percent from 7.0 million to 10.1 million workers. During the same time, the number of deaths from injuries increased 22 percent, from 963 to 1,171. [6].

Major construction injury rates in Great Britain have risen over recent years with reportable nonfatal injury of 16 per 1000 workers between 2004 and 2007 [7], [8]. Construction is the most dangerous land-based work sector in Europe, after the fishing industry. In the European Union, the fatal accident rate is nearly 13 workers per 100,000 as against 5 per 100,000 for the all sector average [9]. The construction industry, perhaps more than most, is plagued by risk [10], but often this risk is not dealt with adequately, resulting in poor performance with increased costs and time delays [11].

Construction accidents account for more than one third of all industrial incidents over the last 10 years in China [12] [15] and for $42 \%$ of all occupational fatalities in Kuwait [16]. In addition to the loss of life and reduction in the quality of life of construction workers, construction incidents lead to project delays, increased project costs, medical burden, and other negative consequences [17] - [20].

Although security and safety in construction sites are not directly related and have separate responsibilities, they seem to be grouped together in practice. Security of the site is necessary for a lot of reasons, such as: general site safety, unauthorized personnel access control etc. [21].

Statistics on fatalities generally places the construction sector as the second highest industry, only surpassed by the agricultural sector. Among the most common sources of fatalities in construction, falls from heights is the category that accounts for the highest proportion of deaths. Berg attributes falls as the leading cause of deaths in construction worldwide [22]. Berg states the percentage of fatalities from falls on German construction sites accounts for $50 \%$ of all fatalities in that work sector. Brabazon et al. noted that since the Construction Design and Maintenance Regulations were introduced in the UK in 1994, the overall fatality rate had decreased by $10 \%$ [23].
Tam et al. characterized the factors influencing safety performance in the following stark terms: poor safety awareness of top management, lack of training, poor safety awareness of project managers, reluctance to input resources into safety measures, and (in general) reckless operations [24]. Chan et al. indicated that (a) increased safety training; (b) enhanced safety awareness; (c) encouragement to develop a safety management system; and (d) improved safety commitment, are all essential for private property developers to encourage the introduction of adequate and effective safety measure to their projects [25]. Within these broad categories, many studies have attempted to identify the plethora of individual factors that could enhance safety management in the construction industry [26] - [33]. In this regard, Aksorn and Hadikusumo used factor analysis to explore 16 critical success factors that might be used by management in the achievement of project safety [34]. However Davies and Tomasin reported that $70-80 \%$ of all fatalities in the UK each year are attributed to falls [35]. Falls from one level to another, falls on the same level and plant machinery and structures falling and striking, crushing or burying people were accounted for that percentage. On the other hand, when considering only the category "falls of people," $52 \%$ out of the 681 construction-related deaths between 1981 and 1985 were in this category.

Cattledge et al. analyzed construction fatality rates in the United States between 1980 and 1989. They found that $49.6 \%$ of all occupational related fatalities due to falls occurred on construction sites [36]. Also in America, McVittie compared the percentage of fatalities from falls to a different elevation on construction sites in Ontario (Canada) and the United States [37]. In Ontario, between 1988 and 1992, 40\% of all fatalities on building sites were due to falls, while that figure was of 30\% for the United States for the period between 1985 and 1989.

In Asia, Byung Yong Jeong reported on construction related fatalities in South Korea [38]. This study showed that falls from heights accounted for $42 \%$ of all construction related fatalities between 1991 and 1994. Tam and Fung reported the fatality rate among construction workers in Hong Kong during 1985 and 1994 was 86.8 per 100,000 [39]. Approximately fifty percent of construction fatalities have been attributed, in a wide range of studies, is falls from heights. Furthermore, scaffolders, roofers, steel and structural trades have a high risk of fatal accident, though fatalities occur across a wide range of construction occupations. The statistics also show that fatalities are spread across housing construction and general contracting, large and small companies and in both urban and rural regions.

\section{Accidents in Construction Sites of Bangladesh}

The construction work site is often a terrible place with an exceptionally high amount of activities taking place. Workers and equipment move about in hastily, where the main focus is to finish the task at hand. In such an environment it is very common that accidents may take place in construction sites. 
Proc. of the Intl. Conf. on Advances in Civil, Structural and Mechanical Engineering - ACSM 2015.

Copyright (C) Institute of Research Engineers and Doctors, USA .All rights reserved.

ISBN: 978-1-63248-039-2 doi: 10.15224/ 978-1-63248-039-2-102

Some of the most common types of construction site accidents include falls from height, construction site falls, crane accidents, scaffolding accidents, workers being run-over by operating equipment, electrical accidents, trench collapses, fires and explosions, welding accidents and being struck by falling objects. Each of these accidents can be equally unfortunate and equally deadly, and each of these accidents can be totally prevented through effective safety measures. Figure 1 and 2 shows some of the unsafe situations of construction sites in Bangladesh. The most common accidents that frequently takes place in construction sites of Bangladesh are described below:

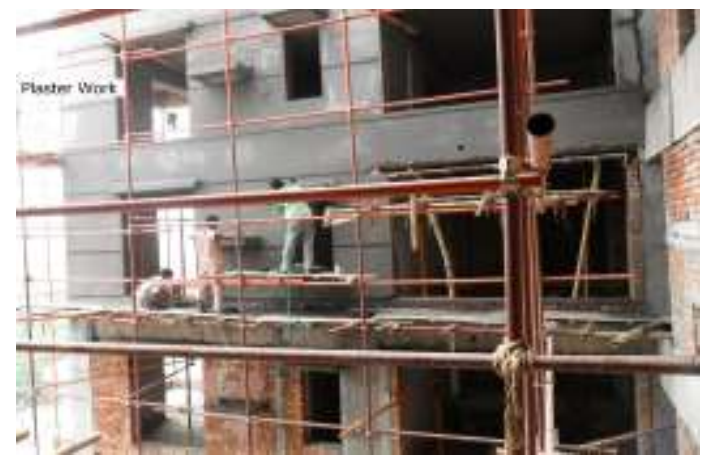

Figure 1. Workers working without any safety precaution (may cause fall accidents to the workers)

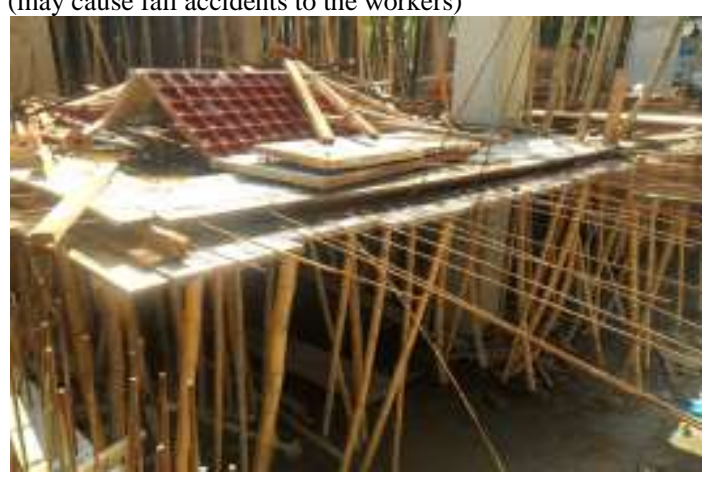

Figure 2. Bamboo props used as scaffolding and no safety net is present (may cause accidents to the pedestrians)

\section{A. Construction Site Falls}

Common construction site falls include falls related with roofs, hoist, scaffolding, elevator shaft, and falling objects. Falls from heights is the leading cause of injury in the construction sites.

There are a variety of roof-related activities that cause great danger in the construction sites for even the most experienced persons also. Roof falls are relatively common in construction work, which are the most common causes of death on the construction sites of Bangladesh.

Scaffolding is a temporary rigid framework used to support construction workers and their materials during the construction or repair of structures. Scaffolds can reach considerable heights and must be built properly in order to ensure the safety of masons working with them. During construction, crane shaft falls can result fatal accidents.
Although there have been reported cases of individuals surviving falls from remarkable heights, a fall of only a couple dozen feet can be fatal in some instances.

\section{B. $\quad$ Electrical Accidents on Construction}

\section{Sites}

In Bangladesh construction workers die every year from electrical accidents. A few causes of these fatalities include electric shock, electrocutions, power line contact and falls caused by contact with electrical power. Direct contact with power lines can result in electric shock and electrocution. Exposure to even low voltage lines can be hazardous or fatal in certain cases also. Defective power tools can claim the lives of many of construction workers if not appropriately maintained or repaired.

\section{Trench Collapse Accidents}

The construction of trenches is needed for many construction tasks. It is absolutely essential that appropriate safety measures are taken during the building process to ensure the safety of all workers involved. When trenches are constructed they must have safeguards in place to protect workers inside the trench from a collapse. When a trench collapses workers may easily become buried under the weight of heavy soil from above. Figure 3 shows trench collapse on a construction site in Bangladesh.

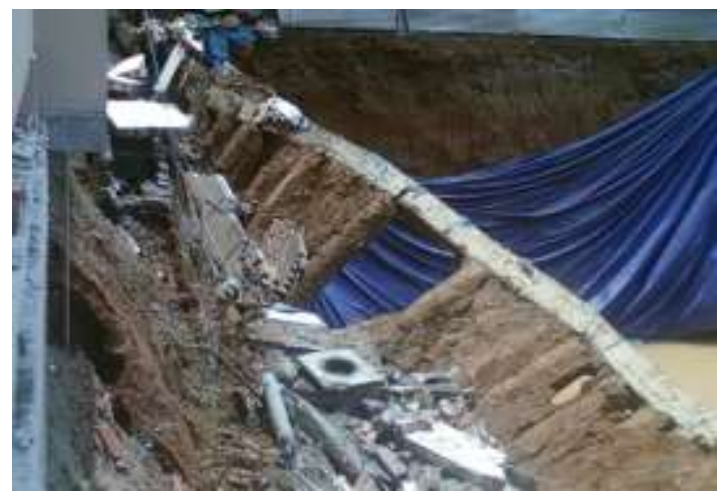

Figure 3. Trench collapse on a construction site

\section{Elevator Accidents on Construction}

\section{Site}

Constructions of high rise structure require elevators to pick up materials to progress of the work and to provide platforms for workers to work. It is heavy temporary structure and requires regular maintenance. Accidents may occur if proper maintenance is not performed. As a result the hazard may lead to fatalities.

There have been terrible and dreadful elevator accidents that have resulted in severe injuries and even in death. Elevator accidents can harm both innocent passengers and the construction workers. Elevator manufacturers', menders, owners, and service companies have a responsibility to ensure the safety of workers and passengers. 
Proc. of the Intl. Conf. on Advances in Civil, Structural and Mechanical Engineering - ACSM 2015.

Copyright (C) Institute of Research Engineers and Doctors, USA .All rights reserved.

ISBN: 978-1-63248-039-2 doi: 10.15224/ 978-1-63248-039-2-102

\section{E. Other Accidents in Construction} Sites

Fire is perhaps the most severe and tragic construction accidents that may occur. A fire plan should exist at construction sites so that workers can be safely evacuated in the event of fires and explosions. Welding is a hazardous activity that requires experience and a strict adherence to safety guidelines. Welding accidents can lead to wide variety of other serious construction-related accidents. Construction equipment, like every other type of machinery, can experience mishap and failure - particularly if it is overused or improperly maintained.

A structure failure takes place when a building or other structure breaks in such a way that it cannot carry as great a load as it could before failure. Structure failures can be catastrophic and result in major injury and loss of life and property. When the safety of the public is compromised for financial gain or time constraints, structure failure may result.

Building collapse can be caused by bad design, faulty construction, foundation failure, extraordinary loads, unexpected failure, or any combination of these causes. A construction worker's worst nightmares are realized if he or she is in a building during its collapse. Victims may be injured, crushed or killed as debris and materials fall down around and over them. However, when a collapse takes place it is a failure of many and a manifestation of irresponsibility and expertise. Lot of accidents also takes place during the demolition works of old buildings. Figure 4 shows an unsafe condition during demolition work.

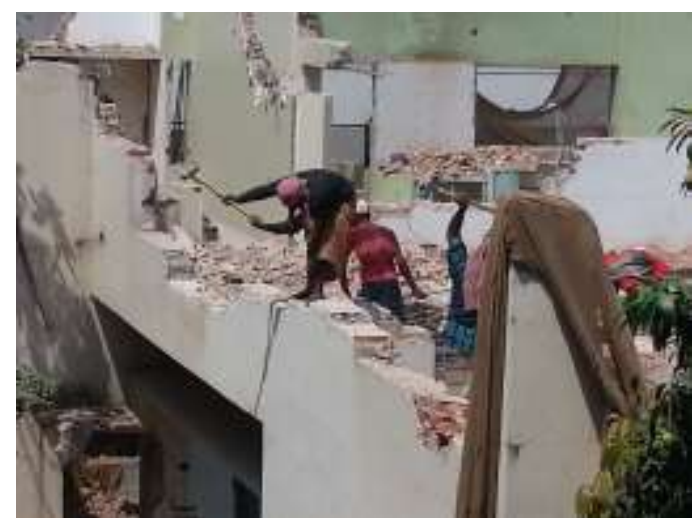

Figure 4. Unsafe condition during demolition work

\section{Iv. Methodology}

\section{A. Introduction}

Few factors were focused in this research which must be taken into account to all construction sites. All the factors are important for the safety workers and surrounding residences. The factors were selected after in depth literature review and site visit of construction projects. These factors are as follows:

i. Awareness of safety procedure

ii. Lack of skill of labors
iii. Clients consciousness
iv. Supervision of Safety Engineer
v. Precaution of fall from construction site
vi. Awareness of scaffolding accident
vii. Precaution of object fall from construction site
viii. Precaution of elevator shaft related accidents
ix. Precaution of electrical accidents

\section{B. Data Collection and Analysis}

Data collection was conducted by questionnaire survey to authorities and personnel's involved in land developers' organization to get a real view of the construction companies' safety condition. The respondent of this survey is sixty eight (68) and all were construction related personnel (Project Engineer, Site Engineer, Resident Engineer, Project Cocoordinator, Project Manager and Assistant Manager). Nine important factors were selected for the questionnaire survey. The respondents were requested to indicate their answers in the questionnaire paper options. Figure 5 shows the overall result of the survey. $78 \%$ of the respondents replied that they

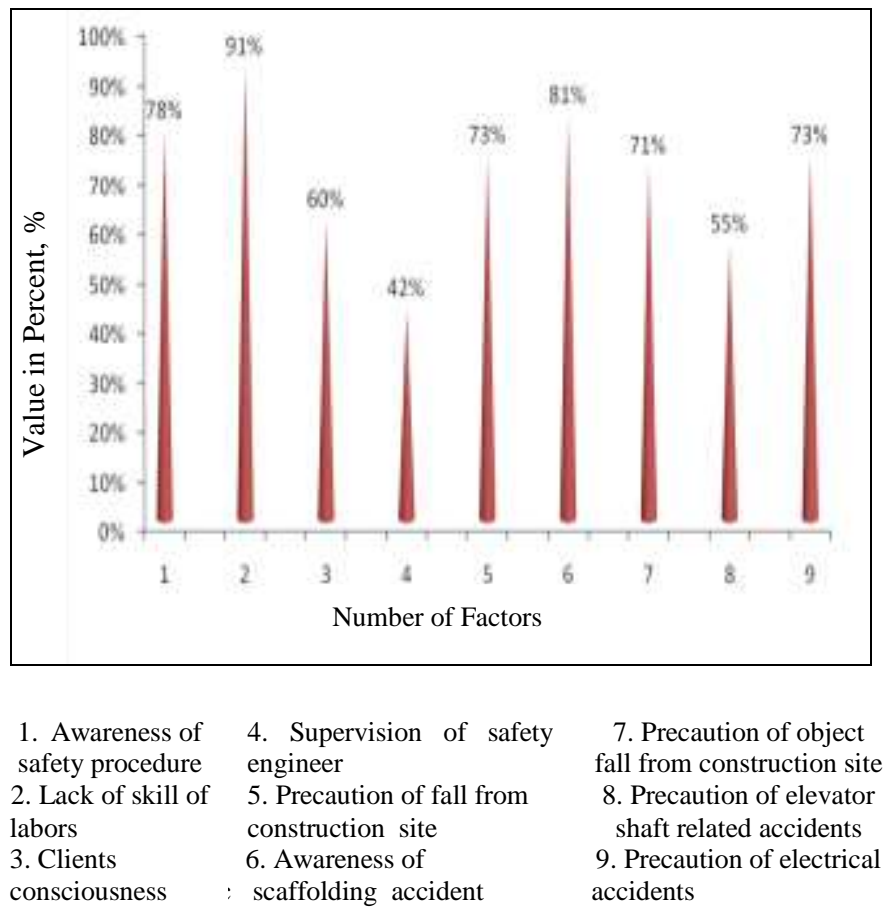

Figure 5. Importance of safety factors

are aware about the safety of construction sites that usually provide safety measures for the workers. Several construction organizations appoint unskilled workers because of their relatively low payment. $91 \%$ of the respondents stated that accidents take place in the construction sites due to the lack of skill of labors. $60 \%$ of the respondents answered that their clients are conscious about safety issues, who eventually arranged safety equipment while $42 \%$ replied that they do not hire safety supervisor for the supervision of construction sites. $73 \%$ of the respondents adopt precaution about the fall from construction sites and $81 \%$ of them are aware of scaffolding accident. In Bangladesh, accidents due to object fall from 
construction sites are becoming severe risk for pedestrians. $71 \%$ of the respondents replied that they usually take care of this factor. The result shows that $55 \%$ of the construction companies take provision about the elevator shaft accidents while $73 \%$ of the respondents usually take precautions to prevent electrical accident.

Figure 6 shows that $34 \%$ of the respondents replied that due to lack of skilled labors $0-20 \%$ of the accidents take place while $26 \%$ said that $41-60 \%$ accidents take place for the same reason. $19 \%$ stated that lack of skilled labors causes $21-40 \%$ of the total accidents in their sites and $11 \%$ said that $81-100 \%$ of their construction site accidents are due to unskilled labors.

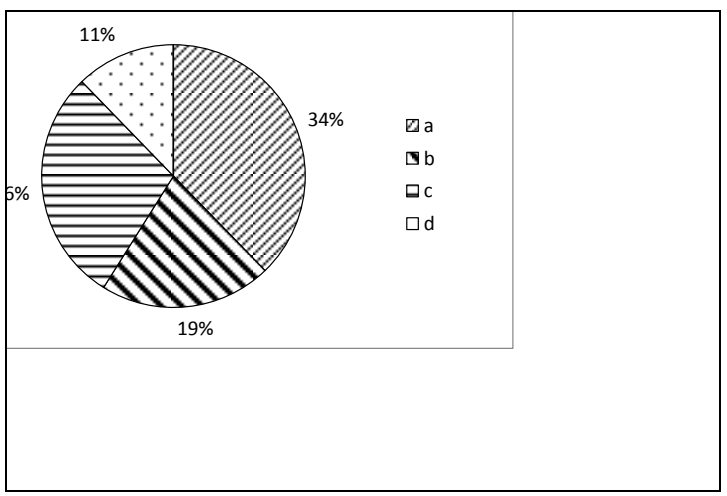

a) $0-20 \%$ b) $21-40 \%$ c) $41-60 \%$ d) $61-80 \%$ e) $81-100 \%$

Figure 6. Percentage of accidents due to unskilled labors

The respondents were requested to rate the safety factors of their sites using Likert Scale. The result represented on Table 2 shows that soil protection condition during excavation of their sites is good. The respondents replied that the condition of storage of construction materials, use of power line and safeguard of instrument is poor while elevated work place condition, safety monitoring and fire protection condition is very poor. The condition of formwork is excellent. The result also shows that pedestrian protection condition and safety knowledge of worker is in poor condition.

TABLE II. SAFETY CONDITIONS OF CONSTRUCTION SitES

\begin{tabular}{|l|c|c|c|c|}
\hline \multicolumn{1}{|c|}{ Safety factors } & Excellent & Good & Poor & Very poor \\
\hline $\begin{array}{l}\text { a) Soil protection in } \\
\text { excavation }\end{array}$ & $23.33 \%$ & $33.67 \%$ & $13.33 \%$ & $29.67 \%$ \\
\hline $\begin{array}{l}\text { b) Storage of construction } \\
\text { materials }\end{array}$ & $6.67 \%$ & $35.00 \%$ & $45.00 \%$ & $13.33 \%$ \\
\hline c) Pedestrian protection & $19.00 \%$ & $28.00 \%$ & $40.33 \%$ & $12.67 \%$ \\
\hline d) Use of power line & $9.00 \%$ & $33.00 \%$ & $48.00 \%$ & $10.00 \%$ \\
\hline e) Elevated workplace & $5.00 \%$ & $20.00 \%$ & $35.00 \%$ & $40.00 \%$ \\
\hline f) Safe guard instrument & $6.67 \%$ & $24.00 \%$ & $36.00 \%$ & $33.33 \%$ \\
\hline $\begin{array}{l}\text { g) Safety knowledge of } \\
\text { worker }\end{array}$ & $4.00 \%$ & $12.33 \%$ & $73.33 \%$ & $13.33 \%$ \\
\hline h) Safety monitoring & $13.67 \%$ & $25.33 \%$ & $27.33 \%$ & $33.67 \%$ \\
\hline i) Condition of form work & $40.00 \%$ & $33.33 \%$ & $6.67 \%$ & $20.00 \%$ \\
\hline j) Fire protection & $10.00 \%$ & $10.00 \%$ & $20.00 \%$ & $60.00 \%$ \\
\hline
\end{tabular}

\section{v. Discussion}

From the questionnaire survey it can be seen that most of the respondents are aware about the safety procedures, skill of workers and scaffold accidents. Majority of the respondents adopt precaution about the fall from construction sites and object fall from construction sites. But unfortunately during the site visit these facts were proved to be wrong in many cases. Most of the cases the construction companies do not hire safety supervisor for the supervision of construction sites. But awareness about these factors may develop a safety environment in future days.

There are not enough skilled workers in construction sites of Bangladesh as the skilled labors often take over domination on payment. So, this leads often to choose easy option of hiring unskilled labors. In Bangladesh, accidents due to object fall from construction sites are becoming severe danger for pedestrians. This accident can be avoidable or at least can be reduced by strict rules and regulations. Supervisions are required to mark out the rushed workers and they supposed to be equipped with safety gears while working in a construction site. The number of fatalities at work in the construction sector remains a matter of serious concern for the Government, employers and employees equally [40].

In relation to management strategies, Tam and Fung for example, looked at the effectiveness of the safety management strategies of 45 construction firms in Hong Kong [39]. They reported that most safety schemes, strategies or interventions reduced the accident rates on these sites. These schemes, strategies and interventions included: level of management responsibility, orientation programs, safety personnel on site, safety awards and incentive schemes, post-accident investigation and feedback, safety training and intensity of safety training, presence of safety committees.

Representatives of some developer companies alleged that the workers were reluctant to use safety gear while the construction workers claimed that they do not get most of these gears.

No government body is strictly monitoring occupational hazards at construction sites even though hundreds die each year in Bangladesh. Recently construction sites in Bangladesh are flourishing at a great scale due to incessant demand of the city dwellers. Millions of workers are involved in the construction industry. Most of the private construction firms in the capital are flouting the provisions of the Bangladesh National Building Code 2006 which necessitate them to ensure the safety of workers. Inadequate safety measures increased the number of death of workers in construction sites.

Proper safety equipment and protections are necessary to protect the lives of workers and to preserve the well-being of them. All employees should be trained to understand the proper way to use the safety gears and to identify hazards. The employee or employer both is responsible for providing fall protection systems and to ensure the use of safety systems. Proper knowledge and consciousness about the safety issues may develop a safe environment in construction sites in coming days. 
Proc. of the Intl. Conf. on Advances in Civil, Structural and Mechanical Engineering - ACSM 2015.

Copyright $(\odot$ Institute of Research Engineers and Doctors, USA .All rights reserved.

ISBN: 978-1-63248-039-2 doi: 10.15224/ 978-1-63248-039-2-102

\section{References}

[1] Report Published on Daily News Papers between 2004-2006.

[2] Report Published on Daily Mirror, "Most construction firms flout safety rules". Bangladesh Institute of Labor Studies (BILS) IDEB Bhaban, Kakrail, Dhaka, July 22, 2011.

[3] Lipscomb, H. J., Dement, J. M., Nolan, J., Patterson, D., Li, L. \& Cameron, W. Falls in residential carpentry and drywall installation: findings from active injury surveillance with union carpenters. Journal of Occupational and Environmental Medicine, 45, pp .881-90, 2003a.

[4] BLS. Census of fatal occupational injuries. Fatal injuries. Washington, DC: U.S. Department of Labor, Bureau of Labor Statistics, Safety and Health Statistics Program, 2002.

[5] BLS. Survey of occupational injuries and illnesses. Washington, D.C.: U.S. Department of Labor, Bureau of Labor Statistics, Safety and Health Statistics Program. 2002.

[6] Dong, X., Yurong M., and H. Elizabeth. Work-related fatal and nonfatal injuries among construction workers. 1992-2003. The Center to Protect Workers' Rights (CPWR), 2005.

[7] Haslam, R. A., Hide, S. A., Gibb, A. G. F., Gyi, D. E., Pavitt, T., Atkinson, S. and Duff, A. R. Contributing factors in construction accidents. Applied Ergonomics, 36, pp. 401-415, 2005.

[8] Hallowell, M., Safety risk perception in construction companies in the Pacific Northwest of the USA. Construction Management and Economics, 28, pp. 403-413, $2010 \mathrm{~b}$.

[9] "Health and safety at work statistics". Eurostat. European Commission. Retrieved 3 August 2012.

[10] Flanagan, R. and Norman, G. Risk management and construction, Blackwell Scientific, Oxford, 1993.

[11] Thompson, P. A. and Perry, J. G. Engineering Construction Risks, Thomas Telford, London, 1992.

[12] Chua, D. K. H. \& Goh, Y. M. Incident causation model for improving feedback of safety knowledge. Journal of Construction Engineering and Management-Asce, 130, pp. 542-551, 2004.

[13]Li, L. P. \& Wang, S. Trends in injury-related incidence and mortality among inpatients in Guangdong Province in 1997-2001. Biomedical and Environmental Sciences, 17, , pp. 333- 340, 2004.

[14] Tam, C. M., Tong, T. K. L. \& Chan, K. K. Rough set theory for distilling construction safety measures. Construction Management and Economics, 24, pp. 1199-1206, 2006.

[15]Liao, C. W. \& Perng, Y. H. Data mining for occupational injuries in the Taiwan construction industry. Safety Science, 46, pp. 1091-1102, 2008.

[16] Kartam, N. A. \& Bouz, R. G. Fatalities and injuries in the Kuwaiti construction industry. Accident Analysis and Prevention, 30, pp. 805-814, 1998.

[17] Lipscomb, H. J., Dement, J. M. \& Behlman, R. Direct costs and patterns of injuries among residential carpenters, 1995-2000. Journal of Occupational and Environmental Medicine, 45, 875-880, 2003b.

[18] Horwitz, I. B. \& Mccall, B. P. (2004). Disabling and fatal occupational claim rates, risks, and costs in the Oregon construction industry. Journal of Occupational and Environmental Hygiene, 1, 688-698, 1990-1997.

[19] Meerding, W., S., M. \& Beeck, E. F. V. Incidence and costs of injuries in The Netherlands The European Journal of Public Health, 16, pp. 271-277, 2005.

[20] Gavious, A., Mizrahi, S., Shani, Y. \& Minchuk, Y. The costs of industrial accidents for the organization: Developing methods and tools for evaluation and cost-benefit analysis of investment in safety. Journal of Loss Prevention in the Process Industries, 22, pp. 434-438, 2009.

[21] Total Construction Project Management George J. Ritz., 1994, McGrawHill, United States of America.

[22]Berg, U. Safety Campaign "fall risk in construction work" Implementation of Safety \& Health on Construction Sites. Proceedings of the 2nd International Conference of CIB Working Commission W99, Honolulu, Hawaii, March 1999.
[23] Brabazon, P., Tipping, A., Jones, J., Construction health and safety for the new millennium, Contract Research Report 313/2000, Health and Safety Executive, 2000.

[24] Tam, C.M., Zeng, S.X., Deng, Z.M. Identifying Elements of Poor Construction Safety Management in China. Safety Science 42, pp. 569586, 2004.

[25] Chan, D.W.M., Chan, A.P.C., Choi, T.N.Y., An empirical survey of the benefits of implementing pay for safety scheme (PFSS) in the Hong Kong construction industry. Journal of Safety Research 41, pp. 433-443, 2010.

[26] Health and Safety Executive (HSE), Blackspot Construction: A Study of Five Years Fatal Accidents in the Building and Civil Engineering Industries. HMSO, London 1988.

[27] Williamson, A.M., Feyer, A.-M., Cairns, D.R., Industrial differences in accident causation. Safety Science 24, pp. 1-12, 1996.

[28] Jeong, B.Y., Occupational Deaths and Injuries in the Construction Industry. Applied Ergonomics 29, pp. 355-360, 1998.

[29] Haslam, R.A., Hide, S.A., Gibb, A.G.F., Gyi, D.E., Pavitt, T., Atkinson, S., Duff, A.R., Contributing factors in construction accidents. Applied Ergonomics 36, pp. 401-415, 2005.

[30] Tariq, S.A., John, G.E. Identifying root causes of construction accidents. Journal of Construction Engineering and Management 126, pp. 52-60, 2000.

[31] Kartam, N.A., Flood, I., Koushki, P., Construction safety in Kuwait: issues, procedures, problems, and recommendations. Safety Science 36, pp. 163-184, 2000.

[32] Angela, C.M., Inês, L.S., Analysis of Occupational Accidents in Portugal between 1992 and 2001. Safety Science 43, pp. 269-286, 2005.

[33] Cheng, C.W., Leu, S.S., Lin, C.C., Fan, C., Characteristic analysis of Occupational Accidents at Small Construction Enterprises. Safety Science 48, pp. 698-707, 2010b.

[34] Aksorn, T., Hadikusumo, B.H.W., Critical success factors influencing safety program performance in Thai construction projects. Safety Science 46, pp. 709-727, 2008.

[35] Davies, V.J., Tomasin, K., Construction safety handbook 2nd Ed. Thomas Telford Publishing 1996.

[36] Cattledge GH, Hendricks S, Stanevich R., Fatal occupational falls in the US construction industry, 1980-1989, Accident Analysis and Prevention 28: (5) 647-654 SEP 1996.

[37] McVittie, D., Banikin, H., Brocklebank, W., The effects of firm size on injury frequency in construction, safety science, Vol. 27, No.1, No.19-23, 1997.

[38] Byung, Yong, Jeong,. Occupational Deaths and Injuries in the Construction Industry, Applied Ergonomics Vol 29 No 5, 1998.

[39] Tam, C., M., and Fung, Ivan., W., H., Effectiveness of Safety Management Strategies on Safety Performance in Hong Kong. Construction Management and Economics, Vol 16, pp. 49-55, 1998.

[40] HAS Code of Practice for Access and Working Scaffolds. Health and Safety Authority, 10 Hogan Place Dublin 2, 1999. 